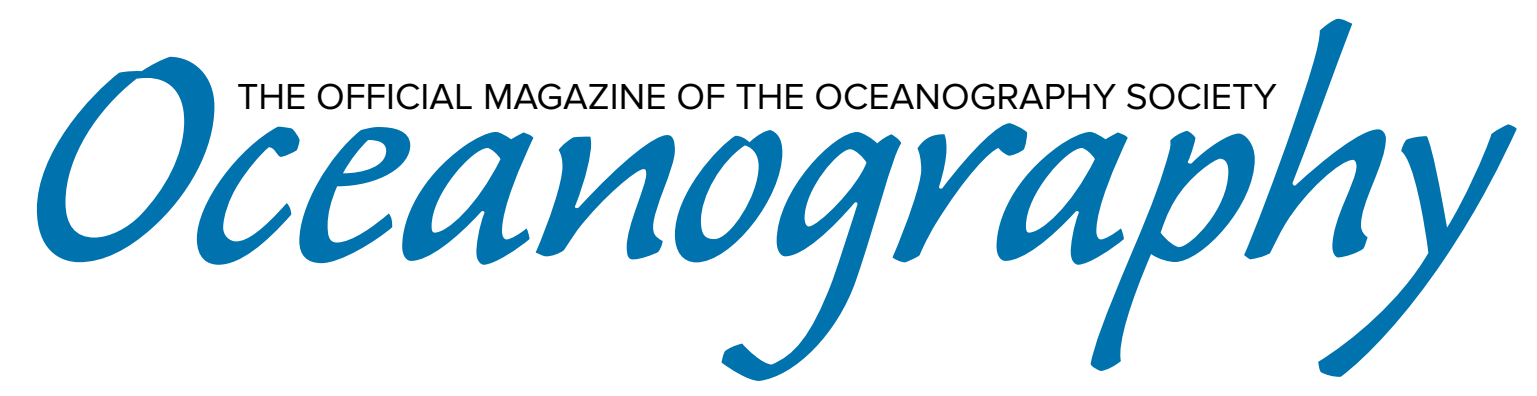

CITATION

Boxall, S. 2018. You say color, I say colour, she says colugo.

Oceanography 31(3):104-105, https://doi.org/10.5670/oceanog.2018.315.

$\mathrm{DOI}$

https://doi.org/10.5670/oceanog.2018.315

COPYRIGHT

This article has been published in Oceanography, Volume 31, Number 3, a quarterly journal of The Oceanography Society. Copyright 2018 by The Oceanography Society. All rights reserved.

\title{
USAGE
}

Permission is granted to copy this article for use in teaching and research.

Republication, systematic reproduction, or collective redistribution of any portion of this article by photocopy machine, reposting, or other means is permitted only with the approval of The Oceanography Society. Send all correspondence to: info@tos.org or The Oceanography Society, 1 Research Court, Suite 450, Rockville, MD 20850, USA. 


\title{
You Say Color, I Say Colour, She Says Colugo ${ }^{1}$
}

\author{
By Simon Boxall
}

I woke up this morning to my wife chuckling. Someone had posted on her local dog walkers' Facebook page: "Has anyone lost a small long-haired Spaniard? I saw him running down the road $5 \mathrm{~min}$ utes ago wearing just a green collar." The woman who posted this question evidently (1) relied on autocorrect, and (2) did not read her message before hitting the go button. Either that or I must have missed an amazing party with our faculty members the night before...

Correct English (or American, depending on your take) is becoming more and more of an issue in our students' written work. While I do not expect their eloquence to match that of Steinbeck or Shakespeare, I do expect prose that makes sense and follows some semblance of logic-although Shakespearian science phraseology could pose a challenge. The level of both written and spoken English in our students (undergraduate and postgraduate) has taken a dive in recent years. In the UK the government has undertaken countless exercises and initiatives to improve how English as a language is taught in schools, from age four years upward. These schemes change as often as the governments themselves, meaning that as today's students work through the system, they get many mixed messages.

I think part of the problem is around treating English as a subject in its own right. We worry more about grammar and usage terms, rather than how it is used as a working language to express science, art, history, and other subjects. I understand it is important to have a noun, a verb, and a few other bits to make a sensible sentence, but what are appositives and present participles? I, Simon Boxall, find grammar straightforward without this knowledge, and have just unwittingly used both. When my son came home from school and said he had been told to make a sentence using a dangler or dangling modifier (yes-they are real terms) I was totally thrown.

Some years ago I was chair of our local primary (ages 7-11) school's board of governors and, working with the head teacher, we decided to stop specific English lessons and instead incorporate the work in science, history, and geography. The children enjoyed it, and by using English in their everyday work they measurably improved their language skills. The approach was dropped after four years when the next rigid national curriculum (with tests) came in. As students work their way through the school and university system, they see use of English as an aside. Particularly in science, we increasingly assess using short answer and multiple-choice questions such that when a student finally has to write a full essay or dissertation, they lack the aptitude to do so. If I make suggestions as to how the student could improve their essay layout or point out that a sentence has no sense, I always get the same questions back: "I haven't lost any marks for this, have I?" and "Surely if the science is correct, then the English should not matter?" If the student cannot present the work in a clear way, then yes, they will lose marks, and often the science logic is challenged by poor English and/or auto spell-checks that are not proofread. The number of statements where isn't instead of is, or doesn't instead of does, creeps in courtesy of spell-check is quite alarming. These errors really change the sense of the work being presented and the student will always blame the computer for changing what they meant to say!

There are two aspects in all of this. The first is not enough practice in writing English, with an assumption that language does not matter, and the second is the scourge of spell-check. It is important to point out at this stage that the problem is often with fluent (or more often nonfluent) native English speakers. Students who arrive at our faculty from a non-English-speaking background can demonstrate some interesting phraseology, but very quickly, through meticulous attention to detail, their level of written English improves and often outshines the native English speaker. I can identify a student from Poland, Norway, or France because their written work is precise and well structured in its language, and invariably correctly spelled. Nonetheless, some features of non-native English speakers' sentences give their origins away. Italians (and Maltese) use "indeed" to start many of their sentences. On proofreading my first Italian student's $\mathrm{PhD}$ thesis, I asked him how many times he started a sentence with indeed? He looked at me blankly and said none-I counted 176. To him it was

${ }^{1}$ Colugo? I mistyped colour to see what I got in the title. A colugo is a flying lemur-it was a choice of that or colon. 
second nature to kick off with "Indeed..." a written equivalent of prego for an Italian, and every one of my Italian students since has used the word many times in writing.

As an undergraduate, our professors were always pointing out better ways of expressing something, and we generally improved as a result. Now the subject of English has become so separated from science that students complain if we make suggestions about the copy. When I started my $\mathrm{PhD}$, my supervisor sent me off with a book list, which included among the many science texts a copy of Fowlers Modern English Usage and Roget's Thesaurus. I still use both-though the latter is now via an app on my phone. A thesaurus does have to be used with caution. There is no point in throwing long words in when simpler ones will suffice. Making an error in the choice of substitution is also a pitfall. My wife is an associate professor in health sciences at another university and came across a wonderful phrase from a student who wrote: "It is important that midwives maintain contemptuous notes"-though it is hard to know if this was a poor use of a thesaurus, poor spell-check, or if the student just hated her patients.

There are plenty of examples of poor use of English-my big bugbear has always been that data are plural. However, I gave up a couple of years ago in despair of correcting "my data is shown in figure 2," or "The data was collected in less than favourable conditions." No, that was not an additional error in spelling favourable. It just boils down to the colour of your flag-u's must be rarer in the USA. One also finds students no longer write in the third person-they use I, we, my in scientific papers-and in most cases do not really understand what we mean by "do not use the third person" in feedback. I guess these things matter less and are slowly giving way to a more conversational writing style.

We then get to the second of the issues-the dreaded autocorrect or autocomplete. I am convinced students no longer read through what they have written unless English is their second language. We get so many odd phrases it seems impossible they are proofreading their work, though normally we know what they meant by correcting the autocorrect in our minds. The usual suspects are words such as "there" and "their," "accept" and "except," some just annoying and some giving very different meaning. My favo(u)rite in recent months was in an essay making use of simulated organisms in ecosystem models. The student wrote: "I spent some time stimulating orgasms using online models for my research." I suspect-I hope-this choice of words was a lack of adequate proofreading. Students also have an issue with that helpful green line that often appears under some of their sentences as they write. As long as the red ones (for spelling errors) disappear, they seem to think, the green line is just there to say it is all fine? Last week I marked a piece of undergraduate work that was unhindered by any punctuation. Each paragraph was one very long eight- to ten-line sentence and was impossible to follow. For self-interest I put it into Word, and the whole six-page report was underlined in green-not a single red underline admittedly, though lots of poor autocorrects.

So how do we move forward to ensure we don't have a future of papers in science journals reading more like op txt spk or see the extinction of the semicolon and comma from the page habitat in years to come? Students do need to start to practice essay writing again-and the feedback needs to be on their writing style and English as well as the all-important science content. Our final-year students have to write a New Scientist-style article around their research dissertation, and the article is marked equally on style and how well it gets the message across as on science content. In year one, week one we get students to précis a science paper as a formative exercise, and again the feedback focuses as much on English as on science. We also guide them through the editorial process in tutorials and feedback at all stages now and explain that writing clearly is a part of being a scientist. Students are at last taking this message on board as a positive aspect rather than a critique of an unimportant part of their work. Science is still our focus in education, but we are now forced to fill in where schools have dropped the mission of clear and well-written English.

There is also the issue of dyslexia, something that many universities report as being on the increase. I'm not convinced it is. We are just getting better at spotting it and in providing additional support for students. It always amazes me how many dyslexic students get through the educational system without any assessment or support until they arrive at university. It also worries me that they don't get the resources they often need to help them. The resources do work in terms of mentoring, training, and additional time in exams to check material. The results are that students with dyslexia write as well as, and at times better than, the rest of their cohort by year three. In the same way as we already provide off-curriculum support for mathematics for all students who want it, perhaps we should do the same in terms of writing, regardless of whether interested students are dyslexic.

In the meantime, if you see that Spaniard running down your street, please let his owner know. It's way past his dinnertime. @

\section{ARTICLE CITATION}

Boxall, S. 2018. You say color, I say colour, she says colugo. Oceanography 31(3):104-105, https://doi.org/ 10.5670/oceanog.2018.315.

\section{AUTHOR}

Simon Boxall (srb2@noc.soton.ac.uk) is Associate Professor, Ocean and Earth Science, University of Southampton, National Oceanography Centre, Southampton, UK. 